\title{
No iron fertilization in the equatorial Pacific Ocean during the last ice age
}

\author{
K. M. Costa $^{1,2}$, J. F. McManus ${ }^{1,2}$, R. F. Anderson ${ }^{1,2}$, H. Ren ${ }^{3}$, D. M. Sigman ${ }^{4}$, G. Winckler ${ }^{1,2}$, M. Q. Fleisher ${ }^{1}$, F. Marcantonio $^{5}$ \&
} A. C. Ravelo ${ }^{6}$

\begin{abstract}
The equatorial Pacific Ocean is one of the major high-nutrient, low-chlorophyll regions in the global ocean. In such regions, the consumption of the available macro-nutrients such as nitrate and phosphate is thought to be limited in part by the low abundance of the critical micro-nutrient iron ${ }^{1}$. Greater atmospheric dust deposition $^{2}$ could have fertilized the equatorial Pacific with iron during the last ice age - the Last Glacial Period (LGP) - but the effect of increased ice-age dust fluxes on primary productivity in the equatorial Pacific remains uncertain ${ }^{3-6}$. Here we present meridional transects of dust (derived from the ${ }^{232}$ Th proxy), phytoplankton productivity (using opal, ${ }^{231} \mathrm{~Pa} /{ }^{230} \mathrm{Th}$ and excess $\mathrm{Ba}$ ), and the degree of nitrate consumption (using foraminifera-bound $\delta^{15} \mathrm{~N}$ ) from six cores in the central equatorial Pacific for the Holocene (0-10,000 years ago) and the LGP (17,000-27,000 years ago). We find that, although dust deposition in the central equatorial Pacific was two to three times greater in the LGP than in the Holocene, productivity was the same or lower, and the degree of nitrate consumption was the same. These biogeochemical findings suggest that the relatively greater ice-age dust fluxes were not large enough to provide substantial iron fertilization to the central equatorial Pacific. This may have been because the absolute rate of dust deposition in the LGP (although greater than the Holocene rate) was very low. The lower productivity coupled with unchanged nitrate consumption suggests that the subsurface major nutrient concentrations were lower in the central equatorial Pacific during the LGP. As these nutrients are today dominantly sourced from the Subantarctic Zone of the Southern Ocean, we propose that the central equatorial Pacific data are consistent with more nutrient consumption in the Subantarctic Zone, possibly owing to iron fertilization as a result of higher absolute dust fluxes in this region ${ }^{7,8}$. Thus, ice-age iron fertilization in the Subantarctic Zone would have ultimately worked to lower, not raise, equatorial Pacific productivity.
\end{abstract}

The major nutrients for phytoplankton growth (nitrogen, phosphorus and silicon) are supplied to the surface waters of the equatorial Pacific by wind-driven upwelling along the Equator. Their consumption by phytoplankton is thought to be limited in part by the low concentrations of the critical micro-nutrient iron ${ }^{1}$. Successful iron fertilization experiments in the modern ocean ${ }^{9}$ have demonstrated the sensitivity of these regions to changes in the micro-nutrient supply. Dust dissolution is one source of iron to the ocean, and globally increased dust fluxes ${ }^{2}$ may have caused natural iron fertilization during the peak of the LGP. There is evidence for iron fertilization ${ }^{8}$ in the Subantarctic Zone of the Southern Ocean, and the associated carbon storage in the deep ocean may have been responsible for almost half of the carbon dioxide drawdown during the $\mathrm{LGP}^{10}$. However, the effects of increased ice-age dust fluxes on the equatorial Pacific are debated ${ }^{3-6}$, with arguments both for and against iron fertilization, particularly in the eastern equatorial Pacific.
Here we present new proxy data on dust flux $\left({ }^{232} \mathrm{Th}\right.$ flux, see Methods), biological productivity ('export production', the export of organic matter out of surface water, as reconstructed from the opal flux, excess barium flux, and ${ }^{231} \mathrm{~Pa} /{ }^{230} \mathrm{Th}$, for which ${ }^{230} \mathrm{Th}$ and ${ }^{231} \mathrm{~Pa}$ represent excess initial ${ }^{230} \mathrm{Th}$ and ${ }^{231} \mathrm{~Pa}$, respectively) and the degree of nitrate consumption (foraminifera-bound $\delta^{15} \mathrm{~N}$ ) from a north-south transect of six cores from the central equatorial Pacific $\left(0.22^{\circ} \mathrm{S}\right.$ to $6.83^{\circ} \mathrm{N}, 156^{\circ}-161^{\circ} \mathrm{W}$; Extended Data Fig. 1) at two time slices: the Holocene (0-10,000 years ago) and the LGP (17,000-27,000 years ago). The relatively shallow water depths (average $\sim 3,000 \mathrm{~m}$ ) result in low rates of carbonate dissolution and permit the development of robust foraminifera-based radiocarbon age models (Extended Data Fig. 2, Extended Data Table 1). Furthermore, these core sites are far from the eastern continental margins, and so ${ }^{232} \mathrm{Th}$ at these sites predominantly reflects the flux of airborne dust particles ${ }^{2}$. Central equatorial Pacific surface waters are dominantly sourced with nitrate from the Equatorial Undercurrent, which originates in the west ${ }^{11}$. Thus, relative to the tropical Pacific as whole, the $\delta^{15} \mathrm{~N}$ of the nitrate supply in the central equatorial Pacific is unlikely to be particularly sensitive to changes in eastern Pacific denitrification (see Methods).

Because the central equatorial Pacific is far from dust sources, reconstructed dust fluxes are among the lowest ever measured ${ }^{12}$. Core-top dust fluxes along the $160^{\circ} \mathrm{W}$ transect average $11.0 \mathrm{mg} \mathrm{cm}^{-2} \mathrm{kyr}^{-1}$, with a maximum of $12.8 \mathrm{mg} \mathrm{cm}^{-2} \mathrm{kyr}^{-1}$ at $2.46^{\circ} \mathrm{N}$ (Fig. 1a). There is a weak decline in dust flux with increasing latitude $\left(r^{2}=0.42, P=0.88\right)$, with the lowest dust flux $\left(8.8 \mathrm{mg} \mathrm{cm}^{-2} \mathrm{kyr}^{-1}\right)$ at the most northerly core. This negative correlation is in contrast to more easterly $\left(110^{\circ} \mathrm{W}\right.$, $140^{\circ} \mathrm{W}$ ) meridional transects, where the highest dust fluxes occur at the more northerly cores ${ }^{13}$. Relative to the Holocene, ice-age dust fluxes are two to three times greater along the $160^{\circ} \mathrm{W}$ transect, averaging $28.6 \mathrm{mg} \mathrm{cm}^{-2} \mathrm{kyr}^{-1}$, with a maximum of $32.2 \mathrm{mg} \mathrm{cm}^{-2} \mathrm{kyr}^{-1}$, at $2.46^{\circ} \mathrm{N}$. The dust fluxes are remarkably constant as a function of latitude. Overall, the greater dust fluxes during the LGP are consistent with other reconstructions across the equatorial Pacific, which find glacial dust fluxes 0.7 to 3.4 times those of the Holocene (Fig. 2).

However, the expectations of ice-age iron fertilization do not correspond with the observed changes in surface productivity (as determined from opal flux, excess barium flux, ${ }^{231} \mathrm{~Pa} /{ }^{230} \mathrm{Th}$; see Methods). Core-top opal fluxes along the transect at $160^{\circ} \mathrm{W}$ average $47 \mathrm{mg} \mathrm{cm}^{-2} \mathrm{kyr}^{-1}$ and are negatively correlated with latitude $\left(r^{2}=0.90, P=0.31\right)$ (Fig. 1b). The maximum opal flux $\left(70 \mathrm{mg} \mathrm{cm}^{-2} \mathrm{kyr}^{-1}\right)$ occurs at the Equator, which is consistent with higher surface productivity within the equatorial upwelling zone. Compared to the core-top fluxes, glacial opal fluxes are mostly lower, averaging $37 \mathrm{mg} \mathrm{cm}^{-2} \mathrm{kyr}^{-1}$, a finding that is inconsistent with the expectations of local iron fertilization. Glacial fluxes also diminish northward from the Equator, consistent with a stable position for the upwelling.

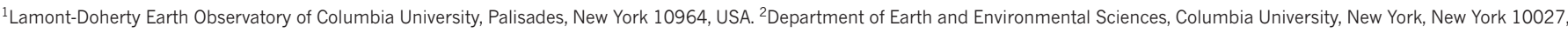
USA. ${ }^{3}$ Department of Geosciences, National Taiwan University, Taipei 106, Taiwan. ${ }^{4}$ Department of Geosciences, Princeton University, Princeton, New Jersey 08544, USA. ${ }^{5}$ Department of Geology and Geophysics, Texas A\&M University, College Station, Texas 77843, USA. ${ }^{6}$ Ocean Sciences Department, University of California, Santa Cruz, California 95064, USA.
} 


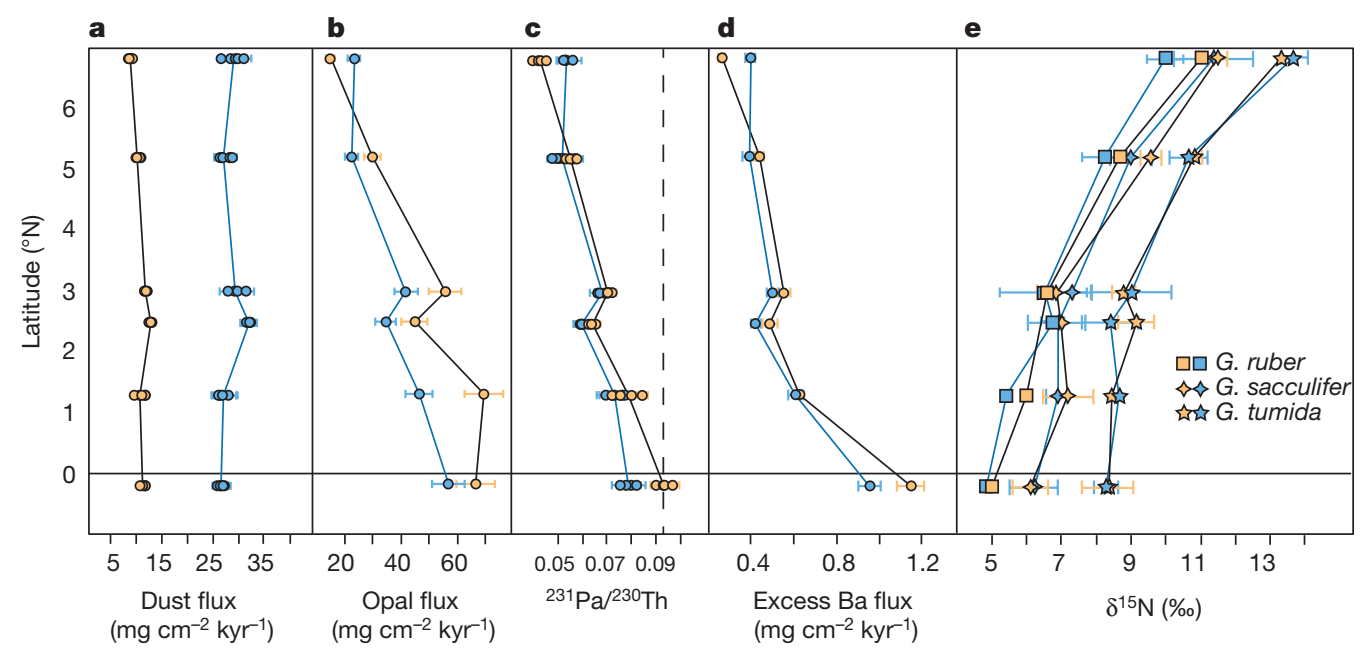

Figure $1 \mid{ }^{230} \mathrm{Th}$-normalized dust flux (see Methods), opal flux, ${ }^{231} \mathrm{~Pa} /{ }^{230} \mathrm{Th}$, excess Ba flux, and $\mathrm{FB}-\delta^{15} \mathrm{~N}$. a-e, Samples from the Holocene (0-10,000 years ago) are orange; samples from the LGP $(17,000-27,000$ years ago) are blue. The magnitude of variability in dust fluxes within the Holocene $(n=30)$ and within the LGP $(n=31)$

The glacial-interglacial productivity signal is corroborated by initial ${ }^{231} \mathrm{~Pa} /{ }^{230} \mathrm{Th}$, an opal flux proxy that has the advantage of being insensitive to remineralization ${ }^{14}$, and excess barium (Ba) fluxes, an independent proxy for total export production ${ }^{15}$. Relative to the Holocene, ${ }^{231} \mathrm{~Pa} /{ }^{230} \mathrm{Th}$ ratios and excess $\mathrm{Ba}$ fluxes are generally lower during the LGP (Fig. 1c, d), except for the northernmost site outside the upwelling zone. The consistent latitudinal trends, with the highest productivity at the Equator and decreasing productivity northward, suggest no major difference in the upwelling regime between the Holocene and the LGP. Furthermore, measured ${ }^{231} \mathrm{~Pa} /{ }^{230} \mathrm{Th}$ ratios are constant throughout each time slice (Extended Data Fig. 3), indicating that our results are not biased by bioturbation of transient extreme values is negligible compared to the more than doubling of dust fluxes in the LGP compared to the Holocene. Error bars are $2 \sigma$ and indicate analytical precision. Error bars on FB- $\delta^{15} \mathrm{~N}$ reflect the variation of samples within the time slice (indicating $2 \sigma$ ). Data for this figure are given in the Source Data for Fig. 1.

(for example, a deglacial productivity maximum ${ }^{16}$ ). The positive correlation between the excess Ba fluxes, ${ }^{231} \mathrm{~Pa} /{ }^{230} \mathrm{Th}$, and opal fluxes (Extended Data Fig. 6) demonstrates that, in this region, siliceous productivity is a proxy for total export production. Accordingly, both core-top and glacial ${ }^{231} \mathrm{~Pa} /{ }^{230} \mathrm{Th}$ from across the equatorial Pacific ${ }^{3,17}$ (Fig. 2) indicate that lower surface productivity was a regional phenomenon during the LGP.

Across much of the global ocean, including most of the tropics and subtropics, the supply of major nutrients limits productivity. Iron limitation generally applies in regions with upwelling or deep mixing, where the major nutrient supply is increased but (given the low iron-to-major-nutrient concentration ratios of most deep waters) iron

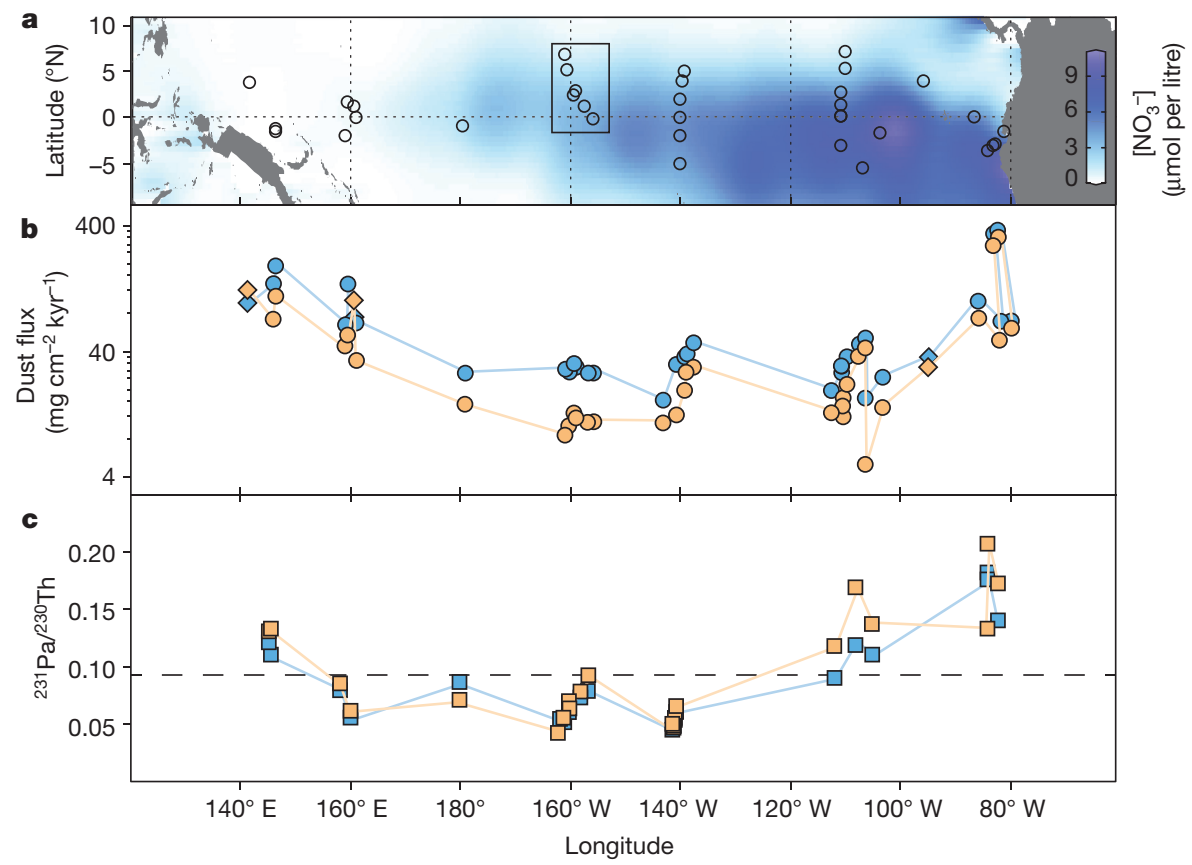

Figure 2 Dust flux and ${ }^{231} \mathrm{~Pa} /{ }^{230} \mathrm{Th}$ across the equatorial Pacific. a, Map of annual average surface nitrate concentrations ${ }^{30}$. Black circles indicate the core locations, and the black box identifies the six new cores presented in this study. b. Dust flux inferred from ${ }^{230} \mathrm{Th}$-normalized ${ }^{232} \mathrm{Th}$ fluxes (circles) and lithogenic accumulation rates (diamonds) for the Holocene ( $0-10,000$ years ago, orange symbols) and the LGP $(17,000-27,000$ years ago, blue symbols). Meridional transects at $110^{\circ} \mathrm{W}$ and $140^{\circ} \mathrm{W}$ are offset longitudinally to clarify the Holocene and LGP time slices. c, ${ }^{231} \mathrm{~Pa} /{ }^{230} \mathrm{Th}$ for the Holocene (orange squares) and the LGP (blue squares). The dashed line represents the production ratio (0.093; see Methods). Data and references for this figure are given in the Source Data for Fig. 2. 
supply is not equivalently increased, leading to incomplete consumption of the major nutrients. Therefore, iron fertilization by dust could drive an increase in the degree of major nutrient consumption in the upwelled surface waters of the equatorial Pacific. The nitrogen isotopic ratio of organic matter bound within the shell walls of planktonic foraminifera (foraminifera-bound $\delta^{15} \mathrm{~N}, \mathrm{FB}-\delta^{15} \mathrm{~N}$ ) covaries with the degree of nitrate consumption ${ }^{8}$, and here we present $\mathrm{FB}-\delta^{15} \mathrm{~N}$ data from two euphotic-zone species (Globigerinoides ruber and G. sacculifer) and one deeper-dwelling species (G. tumida). In both the Holocene and the LGP, FB- $\delta^{15} \mathrm{~N}$ differences among the species parallel depth habitat (Fig. 1e), consistent with previous findings of higher $\mathrm{FB}-\delta^{15} \mathrm{~N}$ in deeper-dwelling species ${ }^{18}$. For each species, FB- $\delta^{15} \mathrm{~N}$ increases northward from the Equator, reflecting the progressive consumption of nitrate as surface waters flow away from the centre of upwelling, with the $\mathrm{FB}-\delta^{15} \mathrm{~N}$ rise accelerating north of $3^{\circ} \mathrm{N}$, as expected when nitrate consumption approaches completion ${ }^{19}$. For each species, core-top and glacial $\mathrm{FB}-\delta^{15} \mathrm{~N}$ are remarkably similar across the meridional transect of cores. The lack of any difference between LGP and Holocene values argues strongly against glacial iron fertilization, which would be expected both to raise $\mathrm{FB}-\delta^{15} \mathrm{~N}$ over the equatorial upwelling and to steepen the northward FB- $\delta^{15} \mathrm{~N}$ increase.

The unchanged relationship between ${ }^{231} \mathrm{~Pa} /{ }^{230} \mathrm{Th}$ and opal flux (Extended Data Fig. 6) also supports sustained iron limitation. Silicification of diatom frustules is thought to be sensitive to iron stress $^{6}$, with more robust and, therefore, better preserved frustules produced under conditions of greater iron limitation. The constancy of the relationship between opal flux and ${ }^{231} \mathrm{~Pa} /{ }^{230} \mathrm{Th}$ (Extended Data Fig. 6), which would be sensitive to changes in opal preservation, indicates that any change in silicification due to iron stress between the LGP and Holocene was too small to alter this relationship measurably.

The lack of ice-age iron fertilization in the equatorial Pacific contrasts with its evident occurrence in the Southern Ocean ${ }^{7,8}$. This dissimilarity may be due to three different factors related to dust fluxes and their fertilizing effects. First, the absolute fluxes of dust to the equatorial Pacific are so low in the Holocene that a doubling or even tripling of these fluxes during the LGP would still have amounted to only a minor atmospheric input of iron. Ice-age dust fluxes in the Subantarctic Zone of the Southern Ocean (500-700 $\left.\mathrm{mg} \mathrm{cm}^{-2} \mathrm{kyr}^{-1}\right)^{7}$ were 20-30 times greater than ice-age dust fluxes in the central equatorial Pacific (20-30 $\mathrm{mg} \mathrm{cm}^{-2} \mathrm{kyr}^{-1}$ ), suggesting that glacial dust in the equatorial Pacific remained roughly an order of magnitude too low to relieve iron limitation. Second, iron in equatorial Pacific dust may be less biologically accessible than the iron in Southern Ocean dust, given that recent work on mineralogical solubility of dust indicates that dust derived from glacial till (as was deposited in the ice-age Southern Ocean) is two to three times more soluble than dust derived from arid soils (as was deposited in the equatorial Pacific) ${ }^{20}$. Third, the concentration of iron upwelled from the Equatorial Undercurrent, the principal regional iron source ${ }^{21}$, is augmented by partial dissolution of fluvial particles eroded from Papua New Guinea ${ }^{22}$. Regionally dry conditions during the $\mathrm{LGP}^{23}$ may have reduced erosion and river transport rates, resulting in lower iron concentrations in the Equatorial Undercurrent that may have countered the small increase in atmospheric deposition of iron, although a full investigation into this negative feedback is beyond the scope of this study.

The combination of lower productivity and the constant degree of nitrate consumption suggests that the nitrate supply in the equatorial Pacific was lower in the LGP than in the Holocene. Reduced nitrate supply could be the result of (1) lower nitrate concentrations in upwelling waters, (2) a deeper thermocline, and (3) lower upwelling rates. Coupled sea surface temperature and productivity records from the eastern equatorial Pacific argue against large differences in upwelling rates between the LGP and the late Holocene ${ }^{24}$. Moreover, in the modern central equatorial Pacific, the degree of nitrate consumption is observed to rise during the springtime minimum in upwelling a Holocene

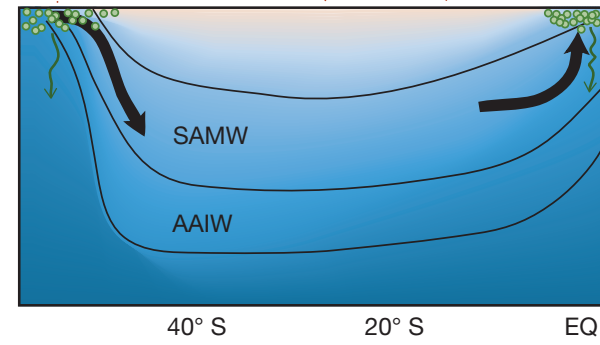

b Last Glacial Period

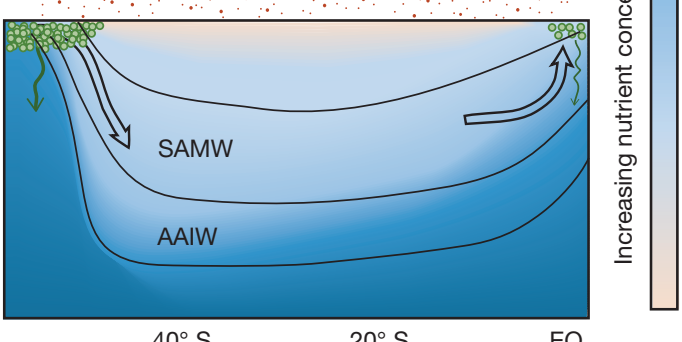

Figure 3 | Changes in nutrient dynamics between the Holocene and the LGP. General circulation shown as black arrows. AAIW, Antarctic Intermediate Water. During the LGP, a 4-6-fold increase in dust supply (red circles) stimulated biological productivity (green circles and arrows) and enhanced the degree of nutrient consumption in the SAMW formation regions to levels much greater than during the Holocene ${ }^{7,8}$ Greater glacial productivity left a smaller inventory of nutrients to be subducted into the thermocline during SAMW formation, thereby lowering the supply of nutrients to equatorial upwelling regions.

rate $^{11}$, and palaeoceanographic data suggest that it also rose during orbitally driven phases of lower upwelling ${ }^{25}$.

Conversely, there is evidence to support both lower major nutrient concentrations in the water upwelled in the equatorial Pacific ${ }^{26}$ and a deeper thermocline ${ }^{27}$ during the LGP. The aforementioned dustdriven enhancement of nitrate consumption in Subantarctic Zone surface waters would have reduced the nitrate concentrations exported in Subantarctic Mode Water (SAMW) to the low latitudes ${ }^{28}$ (Fig. 3). These lower nitrate concentrations in upwelled waters can explain a decline in productivity in spite of a constant degree of nitrate consumption, especially if combined with a deeper thermocline, which would inhibit the entrainment of nutrient-rich waters into the upwelling zone. Furthermore, the constant degree of nitrate consumption suggests that the iron content of the upwelled water was lower during the LGP by the same proportion that major nutrients were lower relative to Holocene concentrations. This parallel response may indicate that the iron content of shallow subsurface waters maintains a relatively constant ratio with the major nutrients, through a conserved iron-to-major-nutrient ratio in sinking organic matter ${ }^{29}$.

This study demonstrates that there was no enhancement of nitrate uptake by dust (iron) fertilization in the equatorial Pacific during the LGP. However, glacial-interglacial changes in dust flux do affect the equatorial Pacific through changes in global nutrient dynamics. Iron fertilization in the Southern Ocean during the LGP generated a higher degree of nutrient consumption, higher surface productivity, and lower nutrient export in the SAMW-formation regions ${ }^{28}$, which reduced the nutrient supply to the equatorial Pacific compared to the Holocene. The inverse correlation between the Subantarctic Zone of the Southern Ocean and equatorial Pacific surface productivity on glacialinterglacial timescales implies that increases in Southern Ocean productivity occur at the expense of equatorial Pacific productivity, a compensating mechanism by which globally integrated ocean productivity would be stabilized over glacial cycles. 
Online Content Methods, along with any additional Extended Data display items and Source Data, are available in the online version of the paper; references unique to these sections appear only in the online paper.

\section{Received 23 February; accepted 9 November 2015.}

1. Brzezinski, M. A. et al. Co-limitation of diatoms by iron and silicic acid in the equatorial Pacific. Deep Sea Res. Part // 58, 493-511 (2011).

2. Winckler, G., Anderson, R. F., Fleisher, M. Q., McGee, D. \& Mahowald, N. Covariant glacial-interglacial dust fluxes in the equatorial Pacific and Antarctica. Science 320, 93-96 (2008).

3. Bradtmiller, L. I., Anderson, R. F., Fleisher, M. Q. \& Burckle, L. H. Diatom productivity in the equatorial Pacific Ocean from the last glacial period to the present: a test of the silicic acid leakage hypothesis. Paleoceanography $\mathbf{2 1}$, PA4201 (2006)

4. Loubere, P., Mekik, F., Francois, R. \& Pichat, S. Export fluxes of calcite in the eastern equatorial Pacific from the Last Glacial Maximum to present. Paleoceanography 19, PA2018 (2004).

5. Murray, R. W., Leinen, M. \& Knowlton, C. W. Links between iron input and opal deposition in the Pleistocene equatorial Pacific Ocean. Nature Geosci. 5 , 270-274 (2012)

6. Pichevin, L. E. et al. Enhanced carbon pump inferred from relaxation of nutrient limitation in the glacial ocean. Nature 459, 1114-1117 (2009).

7. Anderson, R. F. et al. Biological response to millennial variability of dust and nutrient supply in the Subantarctic South Atlantic Ocean. Phil. Trans. R. Soc. Lond. 372, 20130054 (2014).

8. Martinez-Garcia, A. et al. Iron fertilization of the subantarctic ocean during the last ice age. Science 343, 1347-1350 (2014).

9. Boyd, P. W. et al. Mesoscale iron enrichment experiments 1993-2005: synthesis and future directions. Science 315, 612-617 (2007)

10. Hain, M. P., Sigman, D. M. \& Haug, G. H. Carbon dioxide effects of Antarctic stratification, North Atlantic Intermediate Water formation, and subantarctic nutrient drawdown during the last ice age: diagnosis and synthesis in a geochemical box model. Glob. Biogeochem. Cycles 24, 1-19 (2010).

11. Rafter, P. A. \& Sigman, D. M. Spatial distribution and temporal variation of nitrate nitrogen and oxygen isotopes in the upper equatorial Pacific Ocean. Limnol. Oceanogr. http://dx.doi.org/10.1002/Ino.10152 (2015).

12. Kohfeld, K. E. \& Harrison, S. P. DIRTMAP: the geological record of dust. Earth Sci. Rev. 54, 81-114 (2001)

13. McGee, D., Marcantonio, F. \& Lynch-Stieglitz, J. Deglacial changes in dust flux in the eastern equatorial Pacific. Earth Planet. Sci. Lett. 257, 215-230 (2007).

14. Chase, Z., Anderson, R. F., Fleisher, M. Q. \& Kubik, P. W. Scavenging of ${ }^{230}$ Th, ${ }^{231} \mathrm{~Pa}$ and ${ }^{10} \mathrm{Be}$ in the Southern Ocean (SW Pacific sector): the importance of particle flux and advection. Deep Sea Res. Part I/ 50, 739-768 (2003).

15. Hernandez-Sanchez, M. T. et al. Quantifying export production in the Southern Ocean: implications for the $\mathrm{Ba}_{\mathrm{xs}}$ proxy. Paleoceanography $\mathbf{2 6}$, PA4222 (2011)

16. Robinson, R. S., Martinez, P., Pena, L. D. \& Cacho, I. Nitrogen isotopic evidence for deglacial changes in nutrient supply in the eastern equatorial Pacific. Paleoceanography 24, PA4213 (2009).

17. Pichat, S. et al. Lower export production during glacial periods in the equatoria Pacific derived from $\left({ }^{231} \mathrm{~Pa} /{ }^{230} \mathrm{Th}\right)_{\mathrm{xs}, 0}$ measurements in deep-sea sediments. Paleoceanography 19, PA4023 (2004).

18. Ren, H., Sigman, D. M., Thunell, R. C. \& Prokopenko, M. G. Nitrogen isotopic composition of planktonic foraminifera from the modern ocean and recent sediments. Limnol. Oceanogr. 57, 1011-1024 (2012).
19. Altabet, M. A. \& Francois, R. Sedimentary nitrogen isotopic ratio as a recorder for surface ocean nitrate utilization. Glob. Biogeochem. Cycles 8, 103-116 (1994).

20. Schroth, A. W., Crusius, J., Sholkovitz, E. R. \& Bostick, B. C. Iron solubility driven by speciation in dust sources to the ocean. Nature Geosci. 2, 337-340 (2009).

21. Gordon, R. M., Coale, K. H. \& Johnson, K. S. Iron distributions in the equatorial Pacific: implications for new production. Limnol. Oceanogr. 42, 419-431 (1997)

22. Labatut, M. et al. Iron sources and dissolved-particulate interactions in the seawater of the Western Equatorial Pacific, iron isotope perspectives. Glob. Biogeochem. Cycles 28, 1044-1065 (2014).

23. Reeves, J. M. et al. Palaeoenvironmental change in tropical Australasia over the last 30,000 years-a synthesis by the OZ-INTIMATE group. Quat. Sci. Rev. 74, 97-114 (2013).

24. Loubere, P. Marine control of biological production in the eastern equatorial Pacific Ocean. Nature 406, 497-500 (2000).

25. Rafter, P. A. \& Charles, C. D. Pleistocene equatorial Pacific dynamics inferred from the zonal asymmetry in sedimentary nitrogen isotopes. Paleoceanography 27, PA3102 (2012)

26. Loubere, P. Nutrient and oceanographic changes in the Eastern Equatorial Pacific from the last full Glacial to the present. Global Planet. Change 29, 77-98 (2001).

27. Ford, H. L., Ravelo, A. C. \& Polissar, P. J. Reduced El Niño-Southern Oscillation during the Last Glacial Maximum. Science 347, 255-258 (2015).

28. Sarmiento, J. L., Gruber, N., Brzezinski, M. A. \& Dunne, J. P. High-latitude controls of thermocline nutrients and low latitude biological productivity. Nature 427, 56-60 (2004).

29. Ho, T.-Y. et al. The elemental composition of some marine phytoplankton. J. Phycol. 39, 1145-1159 (2003)

30. Conkright, M. E. et al. in NOAA Atlas NESDIS 51 Vol. 4 Nutrients (ed. Levitus, S.) 1-392, ftp://ftp.nodc.noaa.gov/pub/data.nodc/woa/publications/woa01v4d.pdf (US Government Printing Office, 2002).

Acknowledgements We thank M. Soon at the University of British Columbia for assistance in running the opal analyses and M. A. Weigand and S. Oleynik for assistance with the FB- $\delta^{15} \mathrm{~N}$ analyses. Funding was provided in part by NSF award AGS 15-02889 (to J.F.McM., G.W. and F.M.), NSF award OCE-1060947 (to D.M.S.) and the Grand Challenges Program of Princeton University (to D.M.S.) This project also benefited from previous support from the NSF (grant numbers OCE-1003374, OCE-1159053, OCE-1158886) and the Comer Science and Education Foundation (to J.F.McM.) and travel funding from MOST, Taiwan (grant number 103-2116-M-002-032-MY2 to H.R.).

Author Contributions K.M.C., J.F.McM., and R.F.A. designed the study. K.M.C performed the core sampling, U-Th-Pa chemistry, and instrumental analyses, with technical assistance from M.Q.F. Nitrogen isotope analyses were carried out by H.R. (for the Holocene) and K.M.C. with the assistance of H.R. (for the LGP). F.M. performed the barium measurements. All authors contributed to interpretation of the data. K.M.C. wrote the manuscript, and all authors provided comments and revisions.

Author Information All data presented in this manuscript have been deposited in the National Climatic Data Center (https://www.ncdc.noaa.gov/paleo/ study/19441). Reprints and permissions information is available at www.nature.com/reprints. The authors declare no competing financial interests. Readers are welcome to comment on the online version of the paper. Correspondence and requests for materials should be addressed to K.M.C. (kcosta@ldeo.columbia.edu). 


\section{METHODS}

Site location and chronology. The cores used in this study were collected aboard the RV Marcus G. Langseth on a dedicated cruise to the Line Islands in May 2012. The sites range from just south of the Equator $\left(0.22^{\circ} \mathrm{S}\right)$ to approximately $7^{\circ} \mathrm{N}$ along the $159^{\circ} \mathrm{W}\left( \pm 3^{\circ}\right)$ meridian (Extended Data Fig. 1, Extended Data Table 1). Shallow core sites (3,545 $\mathrm{m}$ at the deepest) suggest minimal carbonate dissolution, with carbonate concentrations ranging from $83-98 \mathrm{wt} \%$. Core chronologies were established with four radiocarbon dates on G. ruber: $0 \mathrm{~cm}$ and $8 \mathrm{~cm}$ depth in multicores, and two depths in the Big Bertha piston cores that bracketed the $\delta^{18} \mathrm{O}$ maximum inferred to represent Marine Isotope Stage 2 (ref. 31). Analyses were performed at the National Ocean Sciences Accelerator Mass Spectrometry Facility at Woods Hole Oceanographic Institution and at the Lawrence Livermore National Laboratory. Radiocarbon ages were calibrated to calendar years using Calib 7.0 Marine $13^{32,33}$. Age models were established via linear interpolation between radiocarbon dates (Extended Data Fig. 2, Extended Data Table 2). Coretop ages greater than zero are caused by bioturbation of the surficial sediment, resulting in inflated sedimentation rates in the multicores. Because our samples were selected based on $\delta^{18} \mathrm{O}$ before radiocarbon dating, not all data points fall within the EPILOG definition of the Last Glacial Maximum (the peak of the LGP) of 18,000-24,000 years ago ${ }^{34}$. However, amending the data to only those within that time frame ( $n=21$ of 31 ) has no substantial impact on the interpretations presented here.

Analytical methods. Approximately five samples from the multicores (Holocene) and five samples from the Big Bertha piston cores (LGP) from each of the six sites were analysed for thorium $\left({ }^{230} \mathrm{Th},{ }^{232} \mathrm{Th}\right)$, uranium $\left({ }^{238} \mathrm{U},{ }^{235} \mathrm{U}\right.$, $\left.{ }^{234} \mathrm{U}\right)$, and protactinium $\left({ }^{231} \mathrm{~Pa}\right)$ by isotope dilution inductively coupled plasma mass spectrometry (ICP-MS). Samples $(100 \mathrm{mg}$ ) were randomized, spiked with ${ }^{229} \mathrm{Th},{ }^{236} \mathrm{U}$ and ${ }^{233} \mathrm{~Pa}$, and processed with complete acid digestion and column chromatography ${ }^{35}$. Isotopes were measured on an Element 2 ICP-MS at the Lamont-Doherty Earth Observatory of Columbia University. An internal sediment standard (Line Islands MegaStandard, LIMS) was used for quality control, and replicates of LIMS $(n=15)$ indicate that measurements are reproducible within $<5 \%$ on all isotopes. Excess initial ${ }^{230} \mathrm{Th}$ and excess initial ${ }^{231} \mathrm{~Pa}$ values were calculated by correcting for supported decay (the fraction of ${ }^{230} \mathrm{Th}$ that is in equilibrium with its parent $U$ isotope) from lithogenic and authigenic uranium ${ }^{36}$. These corrections are negligible, with $>98.9 \%$ of the total ${ }^{230} \mathrm{Th}$ scavenged from the water column and present as unsupported ${ }^{230} \mathrm{Th}$ (see section below on ${ }^{230} \mathrm{Th}$ normalization). Dust fluxes are calculated by normalizing the ${ }^{232} \mathrm{Th}$ concentration to ${ }^{230} \mathrm{Th}$ and using an average ${ }^{232} \mathrm{Th}$ concentration in equatorial Pacific dust of 10.7 parts per million ${ }^{13}$. Justification of ${ }^{232} \mathrm{Th}$ as a tracer for aeolian input is provided elsewhere ${ }^{37}$

Biogenic opal was measured by alkaline extraction ${ }^{38}$ at the University of British Columbia (Extended Data Fig. 4). Opal fluxes were calculated by ${ }^{230} \mathrm{Th}$ normalization (see below). Opal fluxes reflect the burial of opal in the sediment, which is a function of both productivity and preservation, and so we compared the opal fluxes to ${ }^{231} \mathrm{~Pa} /{ }^{230} \mathrm{Th}$, which is insensitive to preservation effects ${ }^{14,17}$. Poor opal preservation may be a result of less silicified and thus more easily dissolvable diatom frustules, in response to the higher iron concentrations ${ }^{39-41}$ during the LGP, which would increase the ${ }^{231} \mathrm{~Pa} /{ }^{230} \mathrm{Th}$ to opal ratios. Instead we observe no change in the ${ }^{231} \mathrm{~Pa} /{ }^{230} \mathrm{Th}$ to opal ratio in the time slices presented here: $7.89 \pm 1.24 \times 10^{-3}$ in the Holocene, $8.09 \pm 1.31 \times 10^{-3}$ in the LGP, and $7.60 \pm 0.53 \times 10^{-3}$ overall (Extended Data Fig. 6). The temporal invariance of the ${ }^{231} \mathrm{~Pa} /{ }^{230} \mathrm{Th}$ to opal ratio indicates both that there was no substantial change in diatom silicification due to iron stress and that the degree of opal preservation did not change substantially between the LGP and the Holocene ${ }^{42}$. Therefore we interpret changes in opal flux as changes in productivity.

Barium concentrations were analysed by total digestion at Texas A\&M University of the same samples analysed for biogenic opal (Extended Data Figs 4 and 5). The standard deviation on barium concentration data is $\leq 4.3 \%$, with an average of $2.8 \%$ for all samples. Excess barium concentrations were calculated by subtracting the lithogenic barium component, determined using a lithogenic $\mathrm{Ba} / \mathrm{Th}$ mass ratio of 51.4 in the upper continental crust ${ }^{43}$. Excess barium fluxes were calculated by ${ }^{230} \mathrm{Th}$ normalization (see below). Because dust fluxes are so low in the central equatorial Pacific, the lithogenic Ba fraction is small, $<2 \%$ of the total $\mathrm{Ba}$ in the Holocene and $<6 \%$ of the total $\mathrm{Ba}$ in the LGP. The lithogenic correction is insensitive to variability in the lithogenic $\mathrm{Ba} / \mathrm{Th}$ ratio, so that variations over an order of magnitude $(\mathrm{Ba} / \mathrm{Th}=10-100)$ induce only small deviations $(<10 \%)$ in the excess Ba fluxes (Extended Data Fig. 5). Excess barium in marine sediment is almost exclusively found in the form of barite, a robust sedimentary component insensitive to both dissolution and diagenesis ${ }^{15}$. The excess $\mathrm{Ba}$ flux may reflect the minimum amplitude for the change in productivity, as the proportional difference in excess Ba flux between the LGP and the Holocene (up to $17 \%$ ) is lower than that of ${ }^{231} \mathrm{~Pa} /{ }^{230} \mathrm{Th}$ (up to $19 \%$ ) and the opal flux (up to $33 \%$ ) (Extended Data Fig. 7).

Foraminifera-bound nitrogen isotopes were analysed following the procedure outlined by ref. 18. Approximately $10 \mathrm{mg}$ of Globigerinoides ruber, Globigerinoides sacculifer, and Globorotalia tumida were picked from five Holocene samples and two glacial samples from each of the six sites. Samples were chemically cleaned to remove nitrogen contamination, oxidized with persulfate to convert organic nitrogen to nitrate, measured by chemiluminescence for nitrate concentration, and converted to nitrous oxide by a bacterial denitrifier that lacks a functional nitrous oxide reductase. The $\delta^{15} \mathrm{~N}$ of nitrous oxide was measured by gas chromatography isotope mass spectrometry on a purpose-built nitrous oxide extraction and purification system on-line with a Thermo MAT 253 stable isotope ratio mass spectrometer at Princeton University. $\delta^{15} \mathrm{~N}$ is reported relative to atmospheric $\mathrm{N}_{2}$. Analyses of Holocene samples ( $n=5$ per core) by H.R. and LGP samples $(n=2$ per core) by K.M.C. were performed in the same laboratory following the same procedure. The standard deviation for analysis of a picked and cleaned sample of a given foraminifera species is $\leq 0.3 \%$, while the reproducibility for a given coarse fraction, including the species picking and cleaning, averages $0.3 \%$, with a maximum of $0.8 \%$.

${ }^{230} \mathrm{Th}$ normalization. The concentration of minor sedimentary components, such as opal and excess $\mathrm{Ba}$, can vary in response both to changes in the input of the components themselves as well as to changes in the dilution by major sedimentary components, such as $\mathrm{CaCO}_{3}$. In the Pacific, carbonate is better preserved in glacial periods than in interglacial periods ${ }^{44}$, and in the Line Islands we observed higher $\mathrm{CaCO}_{3}$ concentrations (91\%-93\%) in the LGP than in the Holocene (86\%-91\%) (Extended Data Fig. 4). In the LGP we generally see lower opal and excess Ba concentrations, consistent with increased dilution by $\mathrm{CaCO}_{3}$. To remove the dilution effects and isolate changes in the opal and excess Ba inputs, we normalize to ${ }^{230} \mathrm{Th}$, a constant flux proxy.

${ }^{230} \mathrm{Th}$ and ${ }^{231} \mathrm{~Pa}$ are produced in the water column by the decay of ${ }^{234} \mathrm{U}$ and ${ }^{235} \mathrm{U}$, respectively. Because $\mathrm{U}$ is highly soluble in sea water, it has a long residence time (400,000 years, or $400 \mathrm{kyr}$ ) and a fairly constant concentration (3.2 parts per billion) that scales conservatively with salinity ${ }^{45}$. Thus the production of ${ }^{230} \mathrm{Th}$ and ${ }^{231} \mathrm{~Pa}$ is relatively uniform across the global ocean and depends primarily on the water depth and to a minor extent on salinity. ${ }^{230} \mathrm{Th}$ is produced at a rate of 0.0262 disintegrations per minute (d.p.m.) $\mathrm{m}^{-3} \mathrm{yr}^{-1}\left(\beta_{230}\right)$, while ${ }^{231} \mathrm{~Pa}$ is produced at a rate of $0.00245 \mathrm{dpm} \mathrm{m}^{-3} \mathrm{yr}^{-1}\left(\beta_{231} \text {, measured in activity units }\right)^{46}$. The production ratio of ${ }^{231} \mathrm{~Pa}$ to ${ }^{230} \mathrm{Th}\left(\beta_{230} / \beta_{231}=0.093\right)$ is assumed to be constant across the global ocean.

Unlike U, both Th and Pa are practically insoluble in sea water and thus have relatively short residence times in the ocean (20-40 years and 100-200 years, respectively $)^{47} .{ }^{230} \mathrm{Th}$ and ${ }^{231} \mathrm{~Pa}$ are removed from sea water by scavenging onto settling particles, and they are buried in the underlying sediments unsupported by their parent nuclides. This excess ${ }^{230} \mathrm{Th}$ and ${ }^{231} \mathrm{~Pa}$ in the sediment decays over time with respective half-lives of $75.69 \mathrm{kyr}$ and $32 \mathrm{kyr}$ (ref. 48).

The residence time of ${ }^{230} \mathrm{Th}$ in the ocean is so short (20-40 years) compared to its half-life that virtually all of the ${ }^{230} \mathrm{Th}$ produced by $\mathrm{U}$ decay in sea water is removed to sediments by scavenging. The residence time of ${ }^{230} \mathrm{Th}$ is also much less than the timescale for lateral transport by mixing from regions of low scavenging intensity (low particle flux) to regions of high scavenging intensity. Consequently, throughout the ocean the flux of ${ }^{230} \mathrm{Th}$ carried to the sea bed by sinking particles is within $\sim 30 \%$ of its production rate in the overlying water column ${ }^{36}$. Given a rate of supply that depends mainly on water depth, the concentration of excess ${ }^{230} \mathrm{Th}$ in the underlying sediment is a function of the sediment rain rate, or bulk mass flux (BMF). Higher BMF will dilute the excess ${ }^{230} \mathrm{Th}$ concentration in the sediment. Thus the BMF can be calculated by dividing the integrated ${ }^{230} \mathrm{Th}$ production in the overlying water column $(\beta z)$ by the excess initial ${ }^{230} \mathrm{Th}$, the concentration of excess ${ }^{230} \mathrm{Th}$ in the sediment corrected for decay since deposition ${ }^{36} .{ }^{230} \mathrm{Th}$-normalized fluxes of specific sedimentary components $i$, such as opal and excess $\mathrm{Ba}$, can be calculated as $f_{\mathrm{i}} \times \mathrm{BMF}$, where $f_{\mathrm{i}}$ is the fraction of component $i$ in the sediment. Normalization to ${ }^{230} \mathrm{Th}$ removes the effects of dilution, and it can correct for lateral rather than vertical sediment inputs (such as focusing and winnowing).

The validity of the ${ }^{230} \mathrm{Th}$-normalization technique has generated much debate in the palaeoceanographic community ${ }^{49-51} \cdot{ }^{230} \mathrm{Th}$ systematics have been called into question with regard to (1) dependence on age models and propagated uncertain ties; (2) changes in production of ${ }^{230} \mathrm{Th}$ by uranium decay in the water column (3) size fractionation of ${ }^{230} \mathrm{Th}$ as result of sediment focusing and winnowing; and (4) changes in the local rate of scavenging of ${ }^{230} \mathrm{Th}$ from the water column by sinking particles. Although these present important considerations when interpreting ${ }^{230} \mathrm{Th}$-normalization, several lines of evidence nevertheless justify its usage in this study. 
Anomalously low mass fluxes could be inferred to be a result of erroneously overcorrecting the radioactive decay of excess ${ }^{230} \mathrm{Th}$ in LGP sediments. This uncertainty becomes increasingly important as sediment ages, particularly after several half-lives of ${ }^{230} \mathrm{Th}$ (for example, $>400 \mathrm{kyr}$ ). The relatively short timescales investigated here (15-20 kyr) are unlikely to be sensitive to small changes in the age models, as the age correction from excess ${ }^{230} \mathrm{Th}$ to excess initial ${ }^{230} \mathrm{Th}$ is only of the order of a $1.6 \%-30 \%$ increase in ${ }^{230} \mathrm{Th}$ concentration. For example, to equate the Holocene and LGP equatorial opal fluxes, holding all isotopic concentrations constant, the age of the LGP sample would need to be 2,000 years old rather than 21,400 years old. Such an extreme error in the age assignment can be ruled out because the cores presented here have internally consistent age models constrained by radiocarbon and by $\delta^{18} \mathrm{O}$. Furthermore, evidence for systematic age offsets would be discernible in the ${ }^{231} \mathrm{~Pa} /{ }^{230} \mathrm{Th}$ ratio. Because ${ }^{231} \mathrm{~Pa}$ has a shorter half-life than ${ }^{230} \mathrm{Th}$, the correction for radioactive decay is much more sensitive to age assignments, with the result that the sense of the error in the ${ }^{231} \mathrm{~Pa} /{ }^{230} \mathrm{Th}$ ratio is opposite to the sense of the error in ${ }^{230} \mathrm{Th}$-normalized flux. Increasing the mass flux (for example, by adjusting the sample age to be younger) will simultaneously decrease the ${ }^{231} \mathrm{~Pa} /{ }^{230} \mathrm{Th}$ ratio. The presence of both lower ${ }^{231} \mathrm{~Pa} /{ }^{230} \mathrm{Th}$ and lower ${ }^{230} \mathrm{Th}$-normalized fluxes during the LGP indicates that the lower palaeoproductivity is not an artefact of inaccurate age corrections.

Changes in production of ${ }^{230} \mathrm{Th}$ by uranium decay in the water column are similarly unlikely. The residence time of dissolved uranium in the oceans is so long (200-400 kyr) that the production rate of ${ }^{230} \mathrm{Th}$ cannot change substantially during the 15-20-kyr interval between the LGP and Holocene.

Although sediment winnowing and focusing may influence the absolute ${ }^{230} \mathrm{Th}$ concentrations, it is improbable that they induce relative offsets between the Holocene and the LGP. First, it has been suggested that ${ }^{230} \mathrm{Th}$-normalization of coarse carbonate may be unreliable, but recent evidence ${ }^{52,53}$ supports its utilization in the fine sediment fraction, which is compatible with our application of Th-normalization to dust, barite and opal. Second, focusing factors, which measure the relative contributions of lateral and vertical sediment inputs, are nearly identical within the time slices: $1.28 \pm 0.27$ in the LGP and $1.25 \pm 0.32$ in the Holocene. This consistency between the time slices makes it unlikely that the observed changes in dust flux and productivity are an artefact of the ${ }^{230} \mathrm{Th}$ systematics. Lastly, the slight sediment focusing (focusing factor $>1$ ) at these sites mitigates the grain size and sorting effects on the isotopes that are associated with sediment redistribution ${ }^{54}$ and particularly with winnowing ${ }^{55}$. As pointed out in ref. 55 , moderate variations in lateral focusing do not appear to be influential in modifying the ${ }^{231} \mathrm{~Pa} /{ }^{230} \mathrm{Th}$ isotope ratios or their reflection of the local particle fluxes. The changes observed here are approximately $8 \%$ between time slices.

Finally, ${ }^{230} \mathrm{Th}$-normalization assumes that all $(100 \%)$ of the ${ }^{230} \mathrm{Th}$ produced in the water column is scavenged and buried in the sediment, but lower scavenging efficiencies (for example, $80 \%$ ) would result in lower ${ }^{230} \mathrm{Th}$ concentrations and higher inferred mass fluxes. The only way to increase the scavenging efficiency of ${ }^{230} \mathrm{Th}$ is to increase the flux of particles responsible for scavenging thorium from the water column. The flux of ${ }^{230} \mathrm{Th}$ scavenged from the water column is quite insensitive to changes in particle flux ${ }^{56}$. Although not rigorously calibrated, we might qualitatively estimate that a doubling of particle flux would lead to a $10 \%$ increase in flux of ${ }^{230} \mathrm{Th}$. If the ${ }^{230} \mathrm{Th}$-normalized mass flux were accurate initially, then the result of doubled particle flux would be to underestimate the true flux by $10 \%$. Specifically, we would infer an $81 \%$ increase in flux, whereas the true change would be a $100 \%$ increase. Nevertheless, the reconstructed signal shows the direction of change accurately, even though the amplitude is lower than it should be. Consequently, when we derive a lower particle flux during the LGP using the ${ }^{230} \mathrm{Th}$-normalization method, we can be confident of the direction of the change, and we know that if there is a bias in the derived result then the actual change was even greater than the one we infer.

Denitrification and the $\delta^{15} \mathrm{~N}$ of upwelling waters. The eastern tropical Pacific contains two of the world's largest oxygen-deficient zones. Under these suboxic conditions, bioavailable nitrogen is lost via water column denitrification, which does not go to completion and thus imparts a strong fractionation to the nitrate pool, generating increased $\delta^{15} \mathrm{~N}$ in the residual nitrate. This high $\delta^{15} \mathrm{~N}$ nitrate is distributed from the Oxygen Minimum Zone throughout the Pacific Ocean by circulation and remineralization of organic matter ${ }^{57}$. This $\delta^{15} \mathrm{~N}$ increase is recorded by organic matter deposited in the sediment, so that sedimentary $\delta^{15} \mathrm{~N}$ will tend to increase as a function of denitrification intensity. The influence of denitrification on sedimentary $\delta^{15} \mathrm{~N}$ is highest where partially consumed nitrate from an oxygen-deficient zone is upwelled into the surface, as occurs along the margin of the eastern tropical Pacific ${ }^{16}$; farther afield, the signal is diluted by lower $\delta^{15} \mathrm{~N}$ nitrate and, on a basin and global scale, countered by the input of low $\delta^{15} \mathrm{~N}$ from nitrogen fixation. The net result is that the $\delta^{15} \mathrm{~N}$ of nitrate in the Equatorial
Undercurrent, which upwells in the central equatorial Pacific, is largely unchanged from the initial $\delta^{15} \mathrm{~N}$ of nitrate in Subantarctic Mode Water ${ }^{58}$. The Equatorial Undercurrent originates in the far western Pacific, and its eastward flow is rapid, which may explain why the $\delta^{15} \mathrm{~N}$ of its nitrate is so weakly affected by water column denitrification occurring in the eastern tropical Pacific.

The intensity of water column denitrification has been reconstructed to be lower in the LGP than in the Holocene ${ }^{16,59-63}$. With less elevation in the $\delta^{15} \mathrm{~N}$ of nitrate from the oxygen-deficient zones, bulk sedimentary $\delta^{15} \mathrm{~N}$ was lower by as much as $2.2 \%$ in the eastern tropical Pacific ${ }^{63}$. However, the lower $\delta^{15} \mathrm{~N}$ does not appear to have propagated into the Equatorial Undercurrent. Records from the western equatorial Pacific, where bulk sedimentary $\delta^{15} \mathrm{~N}$ may reflect changes in the Equatorial Undercurrent source water, show little change: $0.03-0.14 \%$ lower in the LGP than in the Holocene ${ }^{25}$. Thus, although we cannot eliminate the potential influence of reduced water column denitrification on the FB- $\delta{ }^{15} \mathrm{~N}$ from the central equatorial Pacific (presented here), we infer that the effects are likely to be minimal. The north-south gradient in $\mathrm{FB}-\delta^{15} \mathrm{~N}$ is insensitive to changes in the $\delta^{15} \mathrm{~N}$ of the nitrate upwelled along the Equator. Thus, the lack of change in this gradient between the Holocene and the LGP is further support that iron fertilization did not drive a substantial increase in nitrate consumption during the LGP, regardless of glacial-interglacial changes in denitrification.

31. Lynch-Stieglitz, J. et al. Glacial-interglacial changes in central tropical Pacific surface seawater property gradients. Paleoceanography $\mathbf{3 0}$, 423-438 (2015).

32. Stuiver, M. \& Reimer, P. J. Extended ${ }^{14} \mathrm{C}$ database and revised Calib $3.0{ }^{14} \mathrm{C}$ age calibration program. Radiocarbon 35, 215-230 (1993).

33. Reimer, P. J. et al. Intcal13 and Marine13 radiocarbon age calibration curves 0-50,000 years cal BP. Radiocarbon 55, 1869-1887 (2013).

34. Mix, A. C., Bard, E. \& Schneider, R. Environmental processes of the ice age: land, oceans, glaciers (EPILOG). Quat. Sci. Rev. 20, 627-657 (2001).

35. Fleisher, M. Q. \& Anderson, R. F. Assessing the collection efficiency of Ross Sea sediment traps using ${ }^{230} \mathrm{Th}$ and ${ }^{231} \mathrm{~Pa}$. Deep Sea Res. Part II 50, 693-712 (2003).

36. Henderson, G. M. \& Anderson, R. F. The U-series toolbox for paleoceanography. Rev. Mineral. Geochem. 52, 493-531 (2003).

37. Anderson, R., Fleisher, M. \& Lao, Y. Glacial-interglacial variability in the delivery of dust to the central equatorial Pacific Ocean. Earth Planet. Sci. Lett. 242, 406-414 (2006).

38. Mortlock, R. A. \& Froelich, P. N. A simple method for the rapid determination of biogenic opal in pelagic marine sediments. Deep-Sea Res. Part A 36, 1415-1426 (1989).

39. Takeda, S. Influence of iron availability on nutrient consumption ratio of diatoms in oceanic waters. Nature 393, 774-777 (1998).

40. Hutchins, D. A. \& Bruland, K. W. Iron-limited diatom growth and Si:N uptake ratios in a coastal upwelling regime. Nature 393, 561-564 (1998).

41. Brzezinski, M. A. The Si:C:N ratio of marine diatoms: interspecific variability and the effect of some environmental variables. J. Phycol. 21, 347-357 (1985).

42. Warnock, J., Scherer, R. \& Loubere, P. A quantitative assessment of diatom dissolution and late quaternary primary productivity in the Eastern Equatorial Pacific. Deep Sea Res. Part I/ 54, 772-783 (2007).

43. Taylor, S. R. \& McLennan, S. M. The geochemical evolution of the continental crust. Rev. Geophys. 33, 241-265 (1995).

44. Farrell, J. W. \& Prell, W. L. Climatic change and $\mathrm{CaCO}_{3}$ preservation: an 800,000 year bathymetric reconstruction from the central equatorial Pacific Ocean. Paleoceanography 4, 447-466 (1989).

45. Owens, S. A., Buesseler, K. O. \& Sims, K. W. W. Re-evaluating the ${ }^{238} \mathrm{U}$-salinity relationship in seawater: implications for the ${ }^{238} \mathrm{U}-{ }^{234} \mathrm{Th}$ disequilibrium method. Mar. Chem. 127, 31-39 (2011).

46. McManus, J. F., Francois, R., Gherardi, J.-M., Keigwin, L. D. \& Brown-Leger, S. Collapse and rapid resumption of Atlantic meridional circulation linked to deglacial climate changes. Nature 428, 834-837 (2004).

47. Hayes, C. T. et al. A new perspective on boundary scavenging in the North Pacific Ocean. Earth Planet. Sci. Lett. 369-370, 86-97 (2013).

48. Cheng, H. et al. The half-lives of uranium-234 and thorium-230. Chem. Geol. $169,17-33(2000)$

49. Francois, R. et al. Comment on 'Do geochemical estimates of sediment focusing pass the sediment test in the equatorial Pacific?' by M. Lyle et al. Paleoceanography 22, PA1216 (2007)

50. Lyle, M., Mix, A. \& Pisias, N. Patterns of $\mathrm{CaCO}_{3}$ deposition in the eastern tropical Pacific Ocean for the last 150 kyr: evidence for a southeast Pacific depositional spike during marine isotope stage (MIS) 2. Paleoceanography 17, 3-1-3-13 (2002).

51. Lyle, M., Pisias, N., Paytan, A., Martinez, J. I. \& Mix, A. Reply to comment by R. Francois et al. on 'Do geochemical estimates of sediment focusing pass the sediment test in the equatorial Pacific?': Further explorations of ${ }^{230} \mathrm{Th}$ normalization. Paleoceanography 22, PA1217 (2007).

52. Lyle, M. et al. Sediment size fractionation and focusing in the equatorial Pacific: effect on ${ }^{230}$ Th normalization and paleoflux measurements. Paleoceanography 29, 747-763 (2014). 
53. Marcantonio, F., Lyle, M. \& Ibrahim, R. Particle sorting during sediment redistribution processes and the effect on ${ }^{230}$ Th-normalized mass accumulation rates. Geophys. Res. Lett. 41, 5547-5554 (2014).

54. McGee, D., Broecker, W. S. \& Winckler, G. Gustiness: the driver of glacial dustiness? Quat. Sci. Rev. 29, 2340-2350 (2010).

55. Kretschmer, S. et al. Fractionation of ${ }^{230} \mathrm{Th},{ }^{231} \mathrm{~Pa}$, and ${ }^{10} \mathrm{Be}$ induced by particle size and composition within an opal-rich sediment of the Atlantic Southern Ocean. Geochim. Cosmochim. Acta 75, 6971-6987 (2011).

56. Yu, E. F., Francois, R., Bacon, M. P. \& Fleer, P. Fluxes of ${ }^{230}$ Th and ${ }^{231} \mathrm{~Pa}$ to the deep sea: implications for the interpretation of excess ${ }^{230} \mathrm{Th}$ and ${ }^{231} \mathrm{~Pa} /{ }^{230} \mathrm{Th}$ profiles in sediments. Earth Planet. Sci. Lett. 191, 219-230 (2001).

57. Sigman, D. M., DiFiore, P. J., Hain, M. P., Deutsch, C. \& Karl, D. M. Sinking organic matter spreads the nitrogen isotope signal of pelagic denitrification in the North Pacific. Geophys. Res. Lett. 36, L08605 (2009).

58. Rafter, P. A., Sigman, D. M., Charles, C. D., Kaiser, J. \& Haug, G. H. Subsurface tropical Pacific nitrogen isotopic composition of nitrate: biogeochemical signals and their transport. Glob. Biogeochem. Cycles 26, GB1003 (2012).
59. Martinez, P. \& Robinson, R. S. Increase in water column denitrification during the last deglaciation: the influence of oxygen demand in the eastern equatorial Pacific. Biogeosciences 7, 1-9 (2010).

60. Altabet, M., Francois, R., Murray, D. E. \& Prell, W. L. Climate-related variations in denitrification in the Arabian Sea from sediment ${ }^{15} \mathrm{~N} /{ }^{14} \mathrm{~N}$ ratios. Nature 373 , 506-509 (1995).

61. De Pol-Holz, R. et al. Melting of the Patagonian ice sheet and deglacial perturbations of the nitrogen cycle in the eastern South Pacific. Geophys. Res. Lett. 33, L04704 (2006)

62. Ganeshram, R. J., Pedersen, T., Calvert, S. E., McNeill, G. W. \& Fontugne, M. R Glacial-interglacial variability in denitrification in the world's oceans: causes and consequences. Paleoceanography 15, 361-376 (2000).

63. Dubois, N. et al. Millennial-scale variations in hydrography and biogeochemistry in the eastern equatorial Pacific over the last $100 \mathrm{kyr}$. Quat. Sci. Rev. 30, 210-223 (2011).

64. Ryan, W. B. F. et al. Global multi-resolution topography synthesis. Geochem. Geophys. Geosyst. 10, Q03014 (2009). 


\section{RESEARCH LETTER}

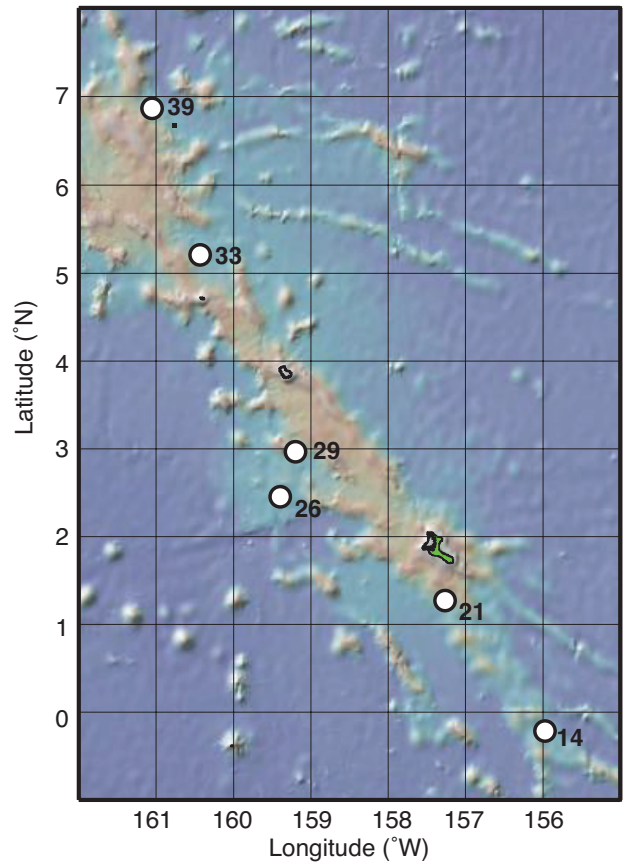

Extended Data Figure 1 | Line Islands core locations. Core sites are identified by their multicore numbers. The respective piston core numbers as well as latitude, longitude and depth are provided in Extended Data Table 1 . The bathymetric map was generated using GeoMapApp ${ }^{64}$. 


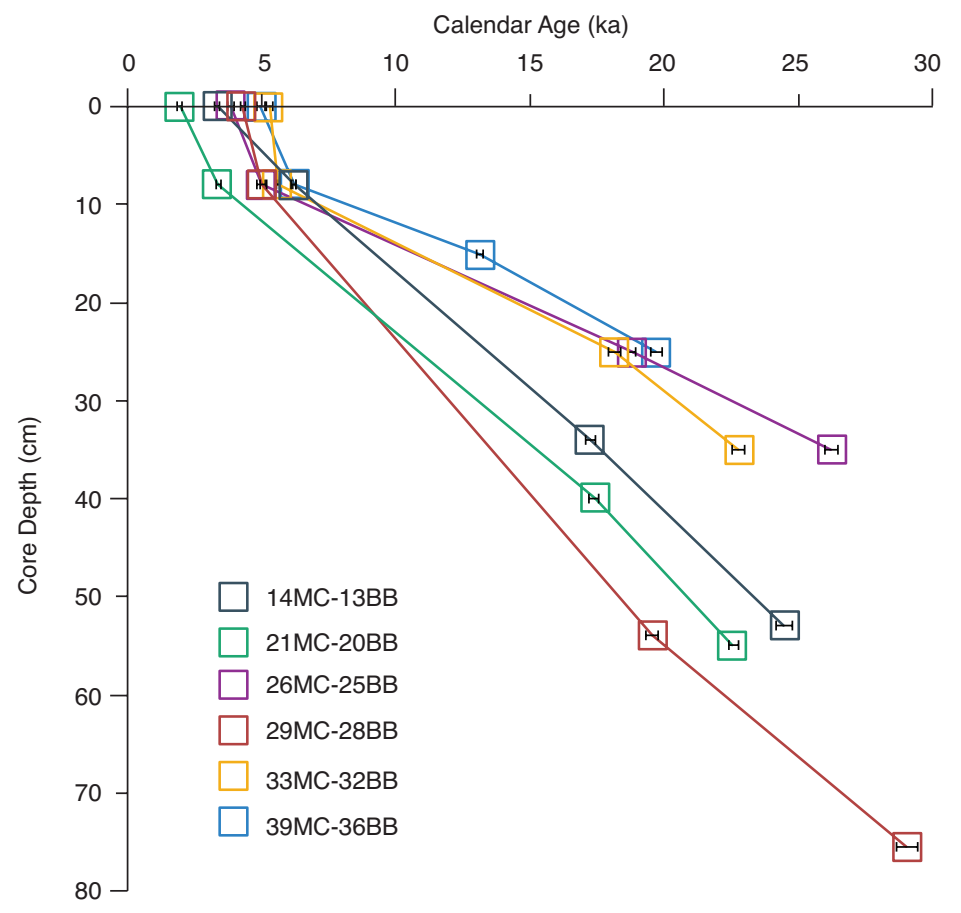

Extended Data Figure 2 | Radiocarbon-based age models for all six cores. Core chronologies were established with four radiocarbon dates on G. ruber: $0 \mathrm{~cm}$ and $8 \mathrm{~cm}$ depth in the multicores (MC), and two depths $(>8 \mathrm{~cm})$ in the Big Bertha piston cores $(\mathrm{BB})$ bracketing the $\delta^{18} \mathrm{O}$ maximum inferred to represent Marine Isotope Stage 2 (ref. 31). Age models were established via linear interpolation between radiocarbon dates

(ka, thousands of years ago), which are provided in Extended Data Table 2. 


\section{RESEARCH LETTER}

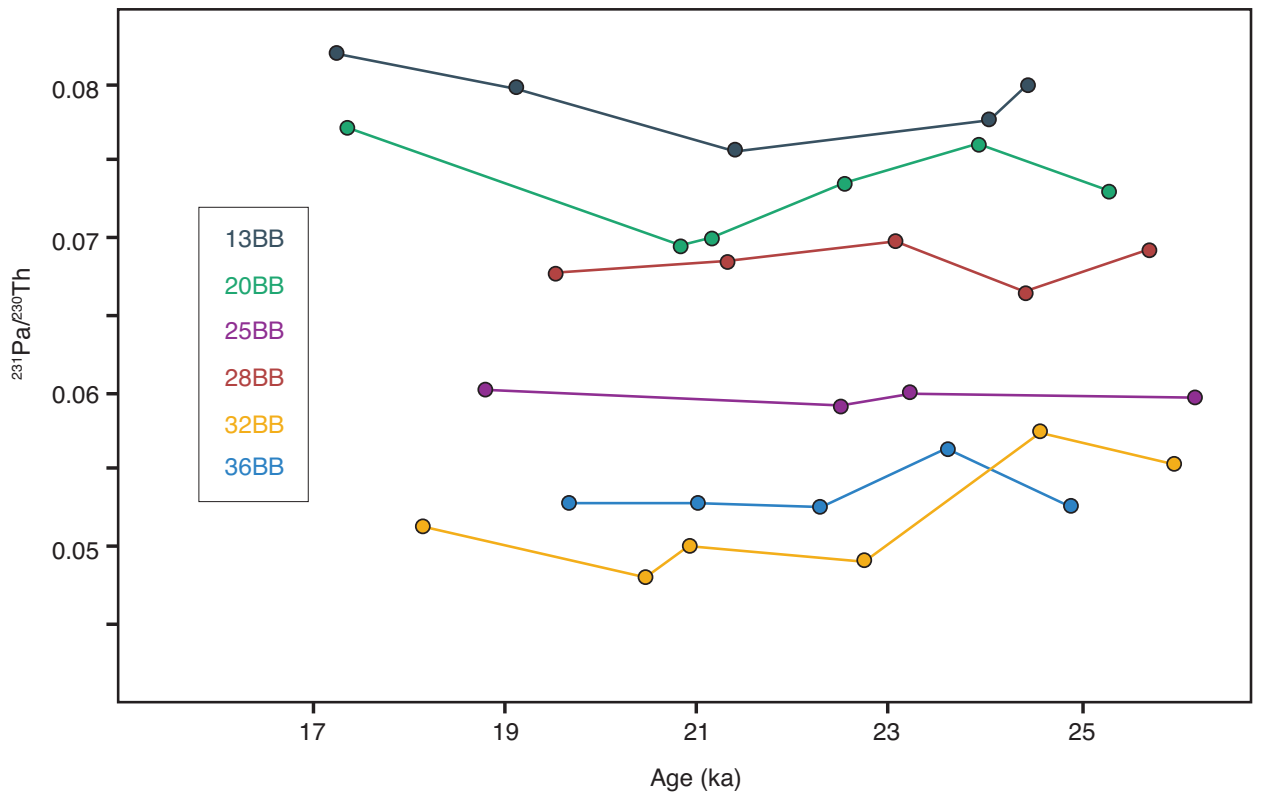

Extended Data Figure $3 \mid$ Time series for ${ }^{231} \mathrm{~Pa} /{ }^{230} \mathrm{Th}$ data within the LGP time slice. The relatively constant values for each core argue against any systematic bias from bioturbation of transient features, such as a deglacial productivity peak. 


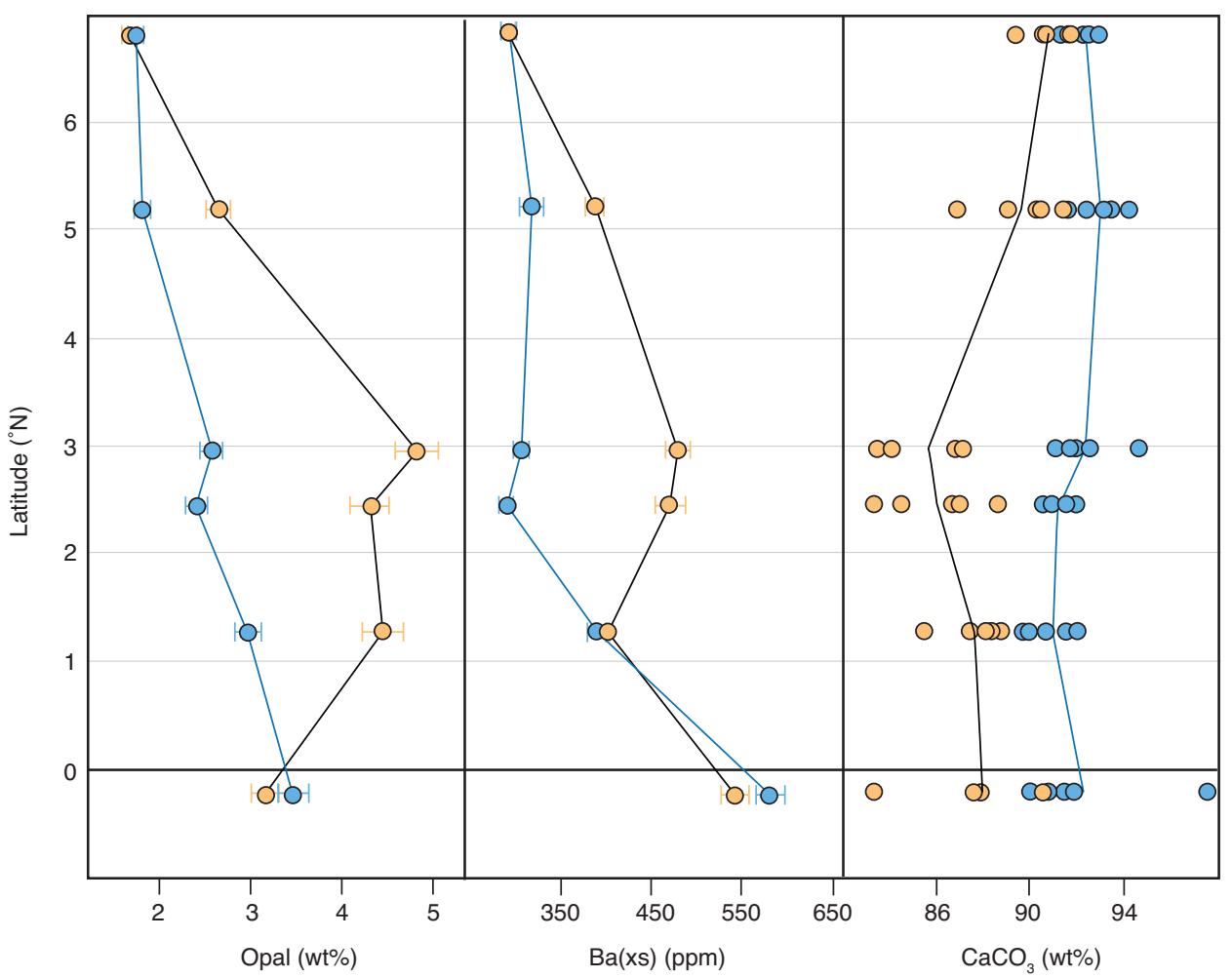

Extended Data Figure 4 | Concentrations of opal, excess $\mathrm{Ba}$ and $\mathrm{CaCO}_{3} \cdot \mathrm{CaCO}_{3}$ is the dominant sedimentary component, and systematic changes in its concentration dilute the concentrations of minor sedimentary components such as opal and excess $\mathrm{Ba}\left(\mathrm{Ba}_{\mathrm{xs}}\right)$. 

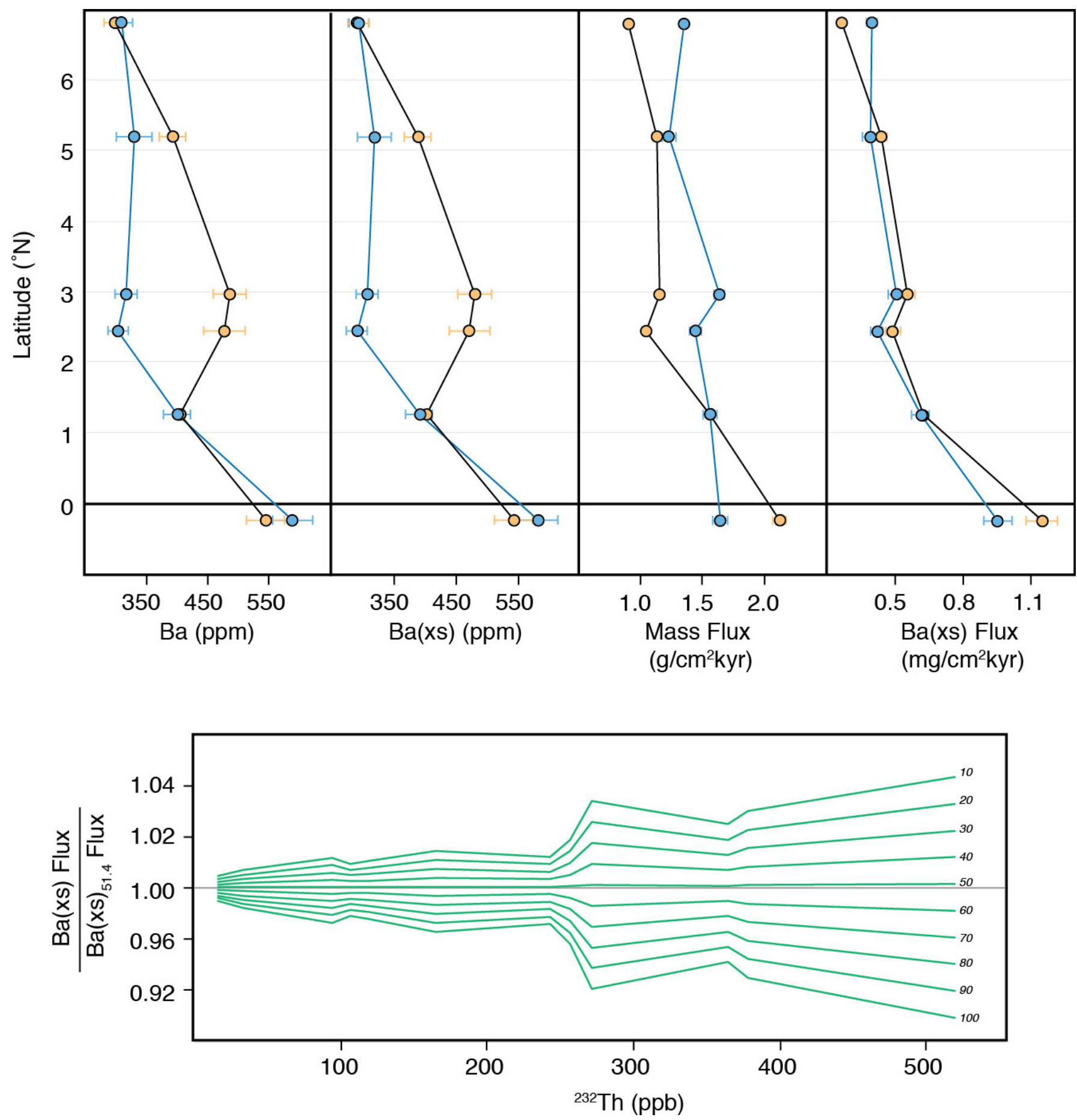

Extended Data Figure 5 | Lithogenic correction for Ba excess flux calculation. Samples from the Holocene (0-10,000 years ago) are orange; samples from the LGP $(17,000-27,000$ years ago) are blue. In the top panel, excess $\mathrm{Ba}$ concentrations were calculated by subtracting the lithogenic $\mathrm{Ba}$ fraction from the total $\mathrm{Ba}$ concentration using a lithogenic $\mathrm{Ba} / \mathrm{Th}$ ratio of 51.4 , based on the average elemental concentrations in upper continental crust $^{43}$. The lithogenic corrections are small, $<2 \%$ for the Holocene and $<6 \%$ for the LGP. Excess Ba concentrations were then multiplied by the total mass flux $\left({ }^{230} \mathrm{Th}\right.$-normalized) in order to generate the excess Ba flux. The bottom panel shows a comparison of excess $\mathrm{Ba}$ fluxes calculated using different lithogenic $\mathrm{Ba} / \mathrm{Th}$ ratios, ranging from 10 to 100 , normalized to the fluxes determined using a $\mathrm{Ba} / \mathrm{Th}$ ratio of 51.4. Ratios less than 51.4 result in slightly higher excess Ba fluxes, while ratios greater than 51.4 result in slightly lower excess Ba fluxes. Overall, the excess Ba fluxes are insensitive to the $\mathrm{Ba} / \mathrm{Th}$ ratio chosen, with deviations only over a range of $\pm 10 \%$. ppm, parts per million; ppb, parts per billion. 


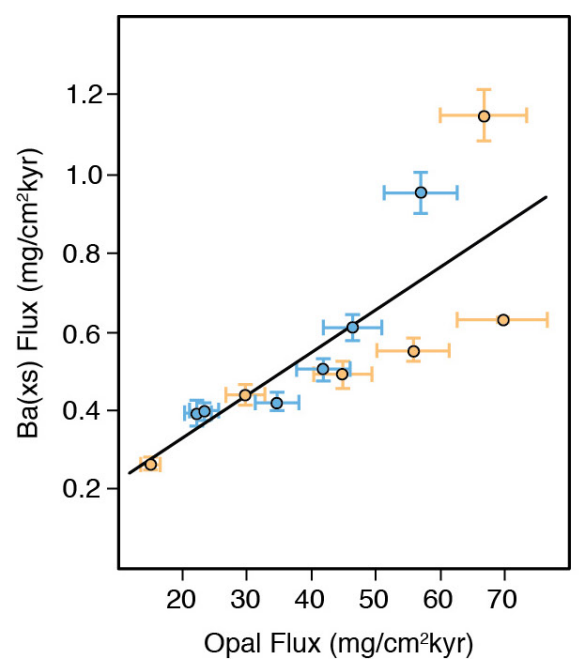

Extended Data Figure $6 \mid{ }^{230}$ Th-normalized opal flux, excess Ba flux, and ${ }^{231} \mathrm{~Pa} /{ }^{230} \mathrm{Th}$. Samples from the Holocene $(0-10,000$ years ago $)$ are orange; samples from the LGP (17,000-27,000 years ago) are blue. ${ }^{231} \mathrm{~Pa} /{ }^{230} \mathrm{Th}$ is positively correlated with the opal flux $\left(r^{2}=0.90, P<0.001\right)$ and excess Ba flux $\left(r^{2}=0.85, P<0.01\right)$. Excess $\mathrm{Ba}$ flux and opal flux are also positively correlated $\left(r^{2}=0.63, P<0.01\right)$. For opal flux, the correlation with ${ }^{231} \mathrm{~Pa} /{ }^{230} \mathrm{Th}$ is especially strong during the LGP (opal flux $r^{2}=0.98$, $P<0.001$ ). The relationship (that is, the slope) between ${ }^{231} \mathrm{~Pa} /{ }^{230} \mathrm{Th}$ and opal flux may be altered by changes in preservation, which affects opal

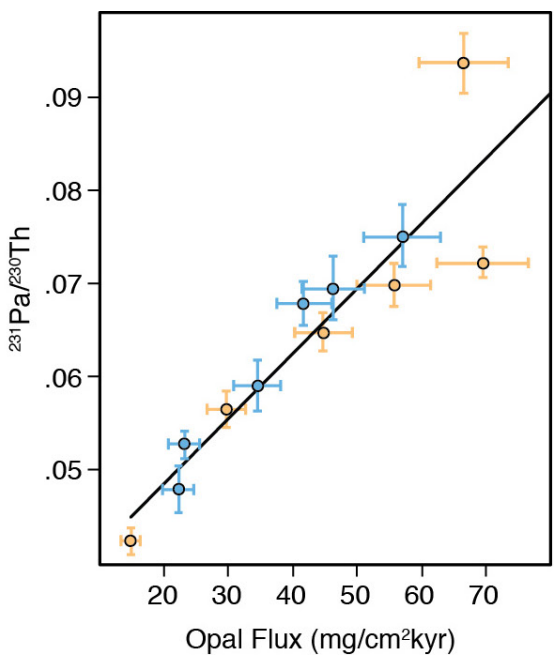

but not ${ }^{231} \mathrm{~Pa} /{ }^{230} \mathrm{Th}$. Poor opal preservation (for example, if the diatom frustules were less silicified) would elevate the ${ }^{231} \mathrm{~Pa} /{ }^{230} \mathrm{Th}$ relative to the sedimentary opal flux, thus steepening the slope. However, the relationship between ${ }^{231} \mathrm{~Pa} /{ }^{230} \mathrm{Th}$ and opal flux is temporally invariant, with slopes of $7.89 \pm 1.24 \times 10^{-3}$ in the Holocene, $8.09 \pm 1.31 \times 10^{-3}$ in the LGP, and $7.60 \pm 0.53 \times 10^{-3}$ overall. We interpret these results to indicate that there was no important change in opal preservation between the LGP and Holocene and, therefore, that frustule silicification (potentially related to iron stress ${ }^{32-34}$ ), similarly remained unchanged. 


\section{RESEARCH LETTER}

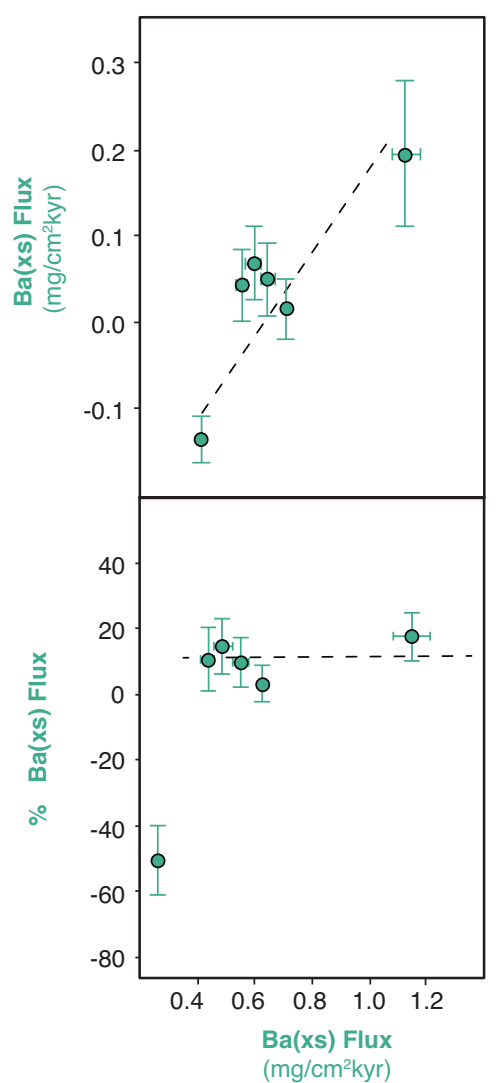

Extended Data Figure $7 \mid$ Absolute and relative change for each productivity proxy versus the Holocene value of that proxy. The absolute change (Holocene minus LGP) in productivity proxy is shown in the top panels; the relative change is shown in the bottom panels. Excess Ba flux is shown in green, opal flux in purple, and ${ }^{231} \mathrm{~Pa} /{ }^{230} \mathrm{Th}$ in red. The greatest change in productivity occurred at the sites with the highest Holocene productivity values. The core that shows a negative change in productivity is the most northerly core $\left(7^{\circ} \mathrm{N}\right)$, which is outside the high-nutrient, low-chlorophyll equatorial upwelling zone, and thus displays different
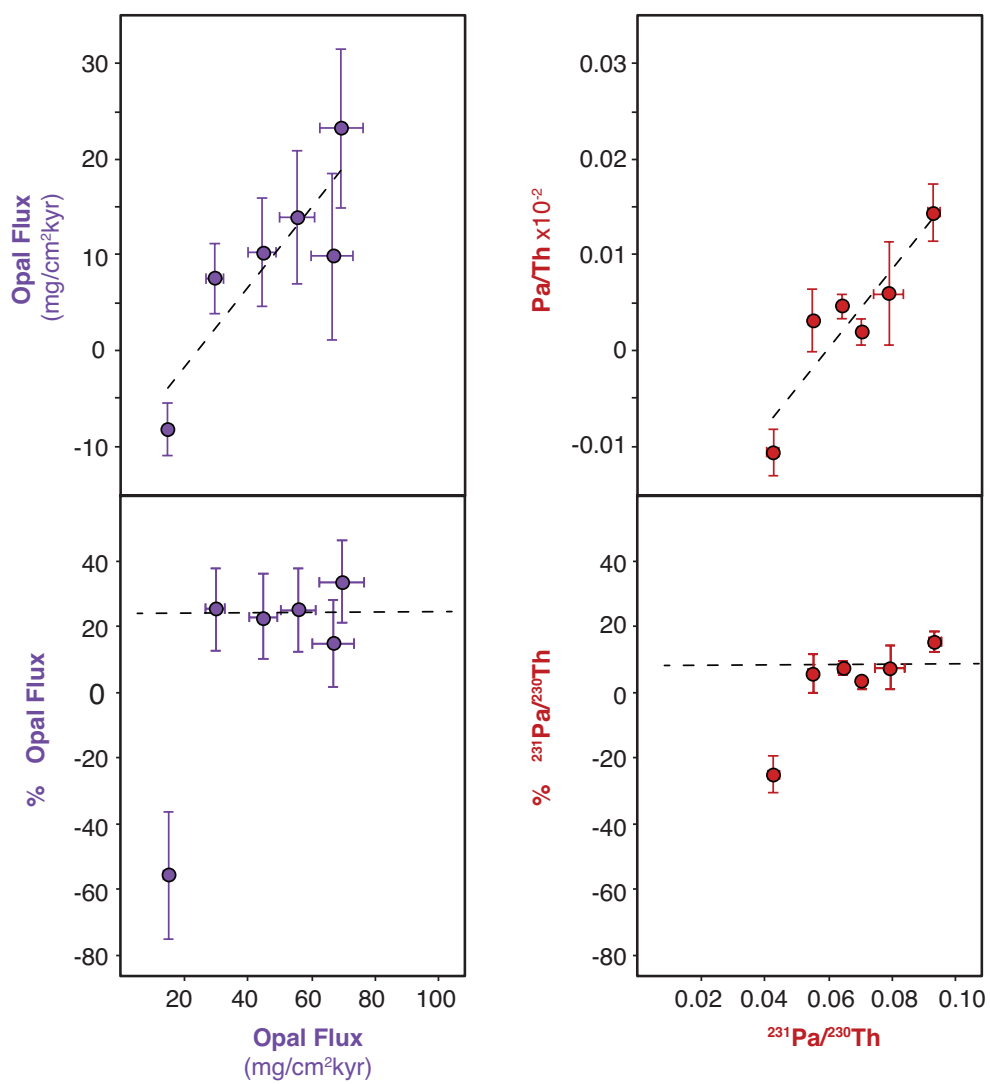

glacial-interglacial nutrient dynamics. The relative change in productivity (Holocene to the LGP) is fairly constant across the five cores within the equatorial upwelling zone at $11 \%$ for excess Ba flux, $24 \%$ for opal flux, and $8 \%$ for ${ }^{231} \mathrm{~Pa} /{ }^{230} \mathrm{Th}$. The inter-proxy difference may reflect a nonlinear scaling of productivity with ${ }^{231} \mathrm{~Pa} /{ }^{230} \mathrm{Th}$, because these radionuclides are scavenged to some extent by all particle phases. In practice, this difference suggests that ${ }^{231} \mathrm{~Pa} /{ }^{230} \mathrm{Th}$ may provide a conservative estimate for changes in productivity, with true productivity changes potentially at much higher amplitude. Error bars are $2 \sigma$ and indicate analytical precision. 
Extended Data Table 1 | Locations of the Line Islands cores

\begin{tabular}{ccccc}
\hline MC \# & BB \# & Lat $\left({ }^{\circ} \mathbf{N}\right)$ & Long $\left({ }^{\circ} \mathbf{W}\right)$ & Depth $(\mathbf{m})$ \\
\hline 14 & 13 & -0.22 & 156.0 & 3049 \\
21 & 20 & 1.27 & 157.3 & 2850 \\
26 & 25 & 2.46 & 159.4 & 3545 \\
29 & 28 & 2.97 & 159.2 & 3152 \\
33 & 32 & 5.20 & 160.4 & 2933 \\
39 & 36 & 6.83 & 161.0 & 2859 \\
\hline
\end{tabular}




\section{RESEARCH LETTER}

Extended Data Table 2 | Radiocarbon ages for age model generation

\begin{tabular}{|c|c|c|c|c|c|}
\hline Core & $\begin{array}{l}\text { Depth } \\
\text { (cm) }\end{array}$ & $\begin{array}{c}\text { Radiocarbon } \\
\text { Age (yrs) }\end{array}$ & \pm & $\begin{array}{c}\text { Calendar Age } \\
\text { (yrs) }\end{array}$ & \pm \\
\hline $14 \mathrm{MC}$ & 0 & 3460 & 35 & 3340 & 110 \\
\hline $14 M C$ & 8 & 5770 & 30 & 6200 & 90 \\
\hline $13 \mathrm{BB}$ & 34 & 14580 & 40 & 17260 & 180 \\
\hline $13 \mathrm{BB}$ & 53 & 20760 & 70 & 24440 & 250 \\
\hline $21 \mathrm{MC}$ & 0 & 2330 & 25 & 1950 & 80 \\
\hline $21 \mathrm{MC}$ & 8 & 3500 & 35 & 3390 & 110 \\
\hline 20BB & 40 & 14685 & 40 & 17400 & 200 \\
\hline $20 \mathrm{BB}$ & 55 & 19100 & 70 & 22540 & 160 \\
\hline $26 \mathrm{MC}$ & 0 & 3900 & 35 & 3880 & 130 \\
\hline $26 \mathrm{MC}$ & 8 & 4740 & 35 & 4980 & 130 \\
\hline $25 \mathrm{BB}$ & 25 & 15950 & 60 & 18800 & 140 \\
\hline $25 \mathrm{BB}$ & 35 & 22400 & 100 & 26200 & 230 \\
\hline $29 M C$ & 0 & 4200 & 15 & 4300 & 80 \\
\hline $29 M C$ & 8 & 4770 & 20 & 5020 & 110 \\
\hline $28 \mathrm{BB}$ & 54 & 16600 & 60 & 19550 & 220 \\
\hline $28 \mathrm{BB}$ & 76 & 25400 & 160 & 29030 & 360 \\
\hline $33 \mathrm{MC}$ & 0 & 4930 & 35 & 5270 & 150 \\
\hline $33 \mathrm{MC}$ & 8 & 5260 & 20 & 5610 & 40 \\
\hline $32 \mathrm{BB}$ & 25 & 15350 & 75 & 18170 & 220 \\
\hline 32BB & 35 & 19300 & 75 & 22750 & 240 \\
\hline $39 \mathrm{MC}$ & 0 & 4730 & 45 & 4960 & 130 \\
\hline $39 \mathrm{MC}$ & 8 & 5800 & 20 & 6230 & 80 \\
\hline $36 \mathrm{BB}$ & 15 & 11650 & 25 & 13150 & 140 \\
\hline $36 \mathrm{BB}$ & 25 & 16700 & 90 & 19670 & 190 \\
\hline
\end{tabular}

Error bars are $2 \sigma$ and indicate analytical precision 